\section{Use of drotrecogin alfa (activated) in a severe acute respiratory syndrome patient with severe sepsis}

To the Editor:

A 34-year-old female health care worker presented to our emergency department with a one-week history of fever, dyspnea, fatigue, arthralgia, myalgia and nonproductive cough. The previous week, our patient had been caring for a patient at the severe acute respiratory syndrome (SARS) index hospital in Toronto, Ontario. She had no significant medical history and was a nonsmoker. Her medications included acetaminophen, ibuprofen and guaifenesin.

On admission, she had a temperature of $36^{\circ} \mathrm{C}$, a blood pressure of $107 / 74 \mathrm{mmHg}$, a heart rate of 144 beats/min and a respiration rate of 45 breaths/min. Her oxygen saturation was $86 \%$ on room air. She was alert but pale, and had oneto two-word dyspnea. She had decreased air entry to the left lung base, decreased fremitus at the left lung base and crackles bilaterally to the apices. Her heart sounds and abdominal examination were unremarkable, and her neurological examination revealed diffuse weakness.

Over the next $12 \mathrm{~h}$, the patient's condition progressively deteriorated. Her white blood cell count was $9.9 \times 10^{9} / \mathrm{L}$, neutrophil count was $8.5 \times 10^{9} / \mathrm{L}$, and prothrombin and partial thromboplastin times were $1.10 \mathrm{~s}$ and $33.5 \mathrm{~s}$, respectively. Her kidney function was normal, and except for an elevated aspartate aminotransferase level ( $92 \mathrm{U} / \mathrm{L})$, her liver enzymes were within normal range.

Despite $100 \%$ fraction of inspired oxygen by mask, the oxygen saturation fell to $90 \%$. Her chest $\mathrm{x}$-ray revealed bilateral interstitial infiltrates. The patient was intubated and mechanically ventilated. A dopamine drip was initiated (at $5 \mu \mathrm{g} / \mathrm{kg} / \mathrm{h}$ ), and she was transferred to the SARS intensive care unit. No immunological or serological assay was available at that early phase in the epidemic to assist in the diagnosis of SARS, so diagnosis was based on the existing World Health Organization criteria (1) documented fever (temperature higher than $38^{\circ} \mathrm{C}$ ), lower respiratory tract symptoms, and contact with a person believed to have had SARS or a history of travel to a geographical area where transmission of illness was documented. The patient was started on empirical treatment with an antiviral therapy (ribavirin) and antibiotics (Zithromax [Pfizer Canada Inc] $500 \mathrm{mg}$ intravenously once a day, and Ceftriaxone [Sandoz Canada Inc] $2 \mathrm{~g}$ intravenously every $24 \mathrm{~h}$ ).

Within $48 \mathrm{~h}$ after hospitalization, the patient had a fever of $38^{\circ} \mathrm{C}$, a blood pressure of $105 / 70 \mathrm{mmHg}$ with a dopamine drip of $5 \mu \mathrm{g} / \mathrm{h}$. Pressure control ventilation with positive end expiratory pressure was continued. Ceftriaxone was discontinued and piperacillintazobactam ( $4.5 \mathrm{~g}$ every $8 \mathrm{~h}$ ) was started. Urine output was maintained at $100 \mathrm{~mL} / \mathrm{h}$ to $200 \mathrm{~mL} / \mathrm{h}$.

Despite aggressive supportive therapy, the patient developed progressive multisystem organ dysfunction. In addition to the existing respiratory and cardiovascular dysfunctions, evidence of hepatic and hematological organ dysfunctions also developed - elevated aspartate aminotransferase level (155 U/L), alanine aminotransferase level (99 U/L) and alkaline phosphatase level $(131 \mathrm{U} / \mathrm{L})$, as well as elevated prothrombin and partial thromboplastin times (1.24 s and $68.7 \mathrm{~s}$, respectively). Her creatinine level doubled to $92 \mu \mathrm{mol} / \mathrm{L}$. There was no evidence of bacterial superinfection.

At this stage, the patient's condition met the established criteria for severe sepsis, and institutional and national guidelines for treatment with drotrecogin alfa (activated) (DrotAA) (2). A $96 \mathrm{~h}$ intravenous infusion of DrotAA at $24 \mathrm{\mu g} / \mathrm{kg} / \mathrm{h}$ was initiated. This was performed because the SARS virus was proving to be very virulent and the patient was deteriorating, as evidenced by progressive organ dysfunctions, despite best standard of care. We also became aware of reports from Hong Kong of high mortality rates in otherwise healthy individuals with SARS (3).

Within two days after initiation of DrotAA, hepatic enzyme levels returned to normal, creatine kinase and lactate dehydrogenase levels decreased, and the patient became afebrile. By the end of the $96 \mathrm{~h}$ infusion, the patient's white blood count had decreased, creatinine levels returned to normal and metabolic acidosis reversed. Dopamine was discontinued the day after completing DrotAA. The patient continued to require ventilatory support and remained in the intensive care unit for three months until her respiratory symptoms resolved. The prolonged need for mechanical ventilation seen in our patient has been reported in other critically ill SARS patients (4-6).

The coagulopathy and inflammation associated with severe sepsis has been reported to be similar regardless of the causative microorganism, and the beneficial effects of DrotAA in treating severe sepsis have also been observed regardless of the infecting microorganism (7).

Recently, insights into the biological mechanisms of action of activated protein $\mathrm{C}$ have been elucidated, including in acute lung injury or acute respiratory distress syndrome $(8,9)$. Most are thought to involve modulation of endothelial function, leukocyte activity or chemotaxis, and improvement of microvascular perfusion (mediated by interaction with protease-activated receptors, sphingosine-1 phosphate pathway, and protein $\mathrm{C}$ receptors on airway

Continued on next page 


\section{LETTER TO THE EDITOR}

epithelial cells and anti-apoptosis). These are in turn thought to improve organ dysfunction.

The present letter cannot establish that DrotAA, antibiotics or antivirals were helpful or harmful. According to current recommendations, however, DrotAA should be considered for patients with severe sepsis, at high risk of death and, putatively, regardless of the causative organism. The experience with our patient supports the further exploration of the use of DrotAA in

\section{REFERENCES}

1. World Health Organization. Case definitions for surveillance of severe respiratory distress syndrome (SARS).

Wkly Epidemiol Rec 2003;78:81-8.

2. Garber G, Gibney RN, Light B, et al. Guidance on patient identification and administration of recombinant human activated protein $\mathrm{C}$ for the treatment of severe sepsis. Can J Infec Dis 2002;13:361-72.

3. Tsang KW, Ho PL, Ooi GC, et al. A cluster of cases of severe acute respiratory syndrome in Hong Kong. N Engl J Med 2003;348:1977-85.

4. Fowler RA, Lapinsky SE, Hallett D, et al. Critically ill patients with severe acute respiratory syndrome. JAMA 2003;290:367-73.

5. Lew TW, Kwek TK, Tai D, et al. Acute respiratory distress syndrome in critically ill patients with severe acute respiratory syndrome. JAMA 2003;290:374-80. the treatment of severe sepsis of diverse etiologies in this context.

Donna McRitchie MD, Warda Farooq MD North York General Hospital, University of Toronto, Toronto, Ontario

Harold N Fisher MD Eli Lilly Canada Inc, Acute Care REDD, Toronto, Ontario

6. Booth CM, Matukas LM, Tomlinson GA, et al. Clinical features and short-term outcomes of 144 patients with SARS in the greater Toronto area. JAMA 2003;289:2801-9.

(Erratum in 2003;290:334).

7. Opal SM, Garber GE, LaRosa SP, et al. Systemic host responses in severe sepsis analyzed by causative microorganism and treatment effects of drotrecogin alfa (activated). Clin Infec Dis 2003;37:50-8

8. Macias WL, Yan SB, Williams MD, et al. New insights into the protein $\mathrm{C}$ pathway: Potential implications for the biological activities of drotrecogin alfa (activated). Crit Care 2005;9:S38-45.

9. Mosnier LO, et al. Mechanism of action of protein $\mathrm{C}$ in cytoprotection. Blood 2007;109:3161-72.

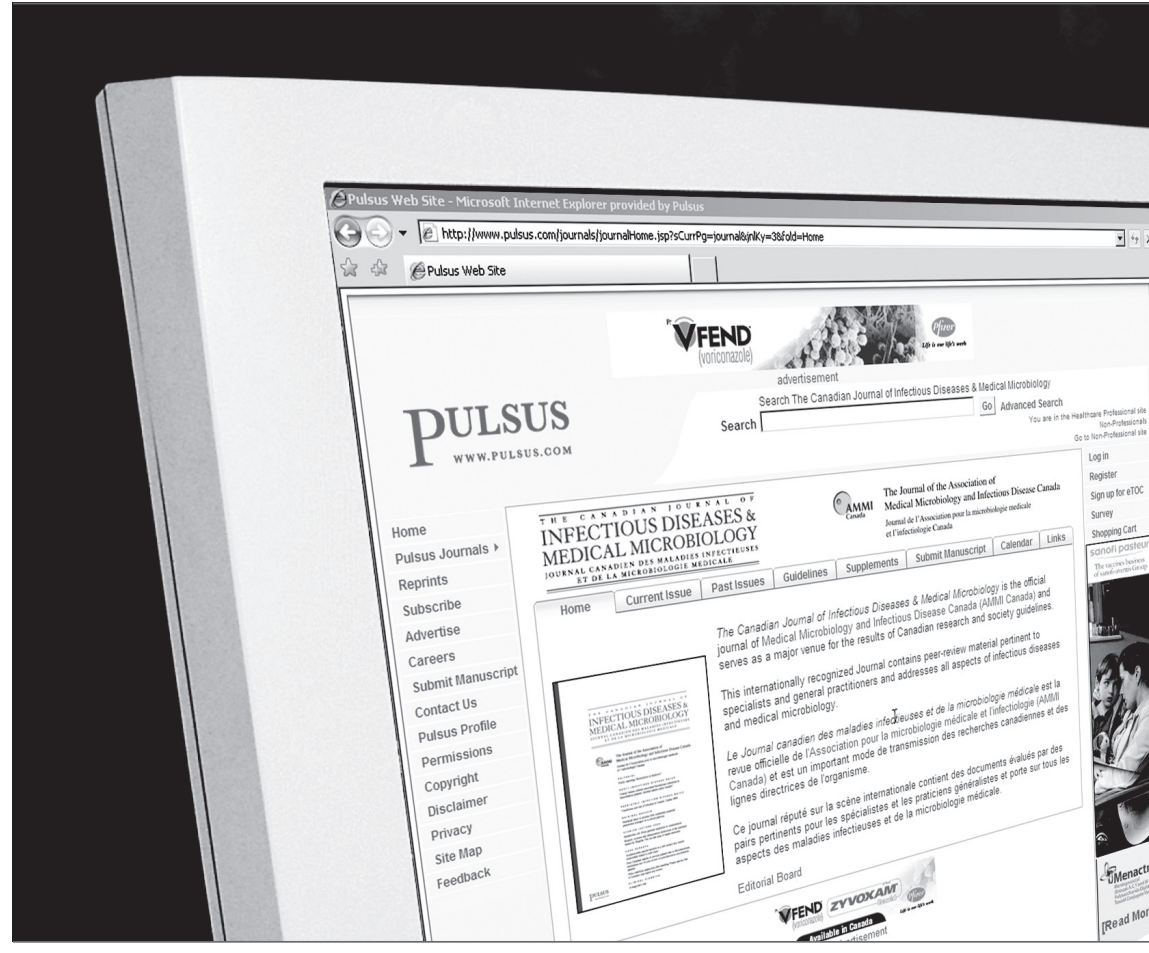

\section{PULSUS \\ WWW.PULSUS. GOM}

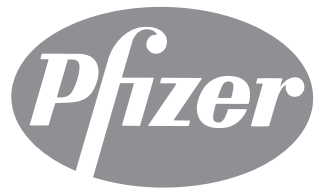

GOLD SPONSOR

\section{sanofi pasteur \\ The vaccines business of sanofi-aventis Group}

SILVER SPONSOR

GENEROUS SUPPORTERS OF

The Canadian Journal

of Infectious Diseases \&

Medical Microbiology website 


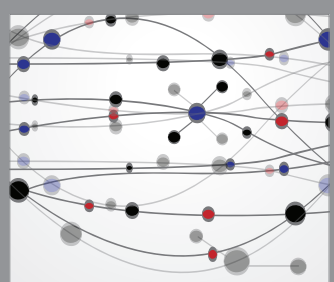

The Scientific World Journal
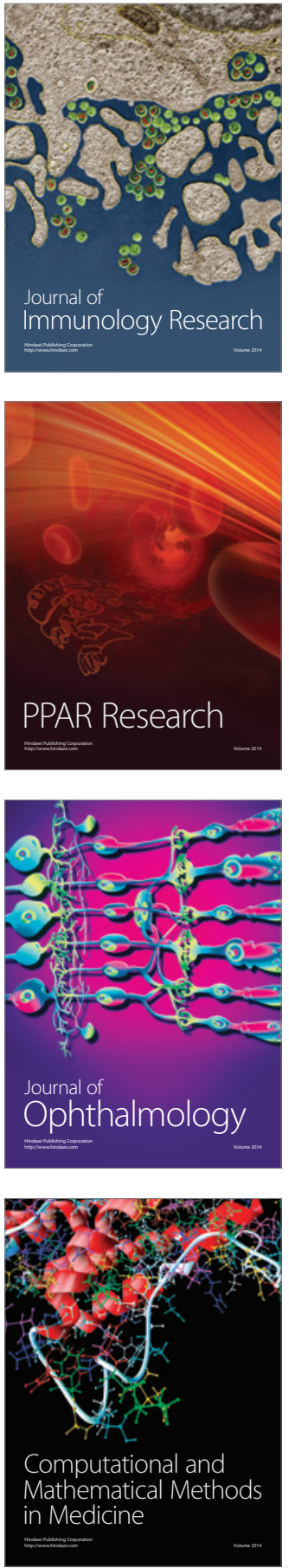

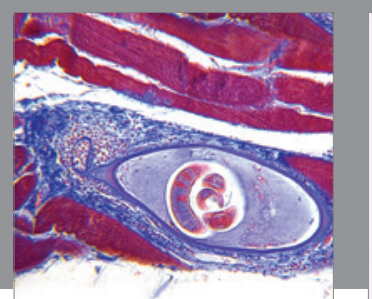

Gastroenterology Research and Practice

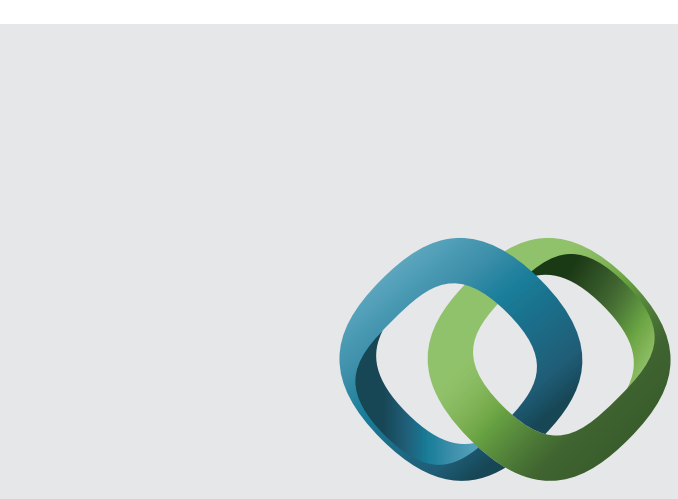

\section{Hindawi}

Submit your manuscripts at

http://www.hindawi.com
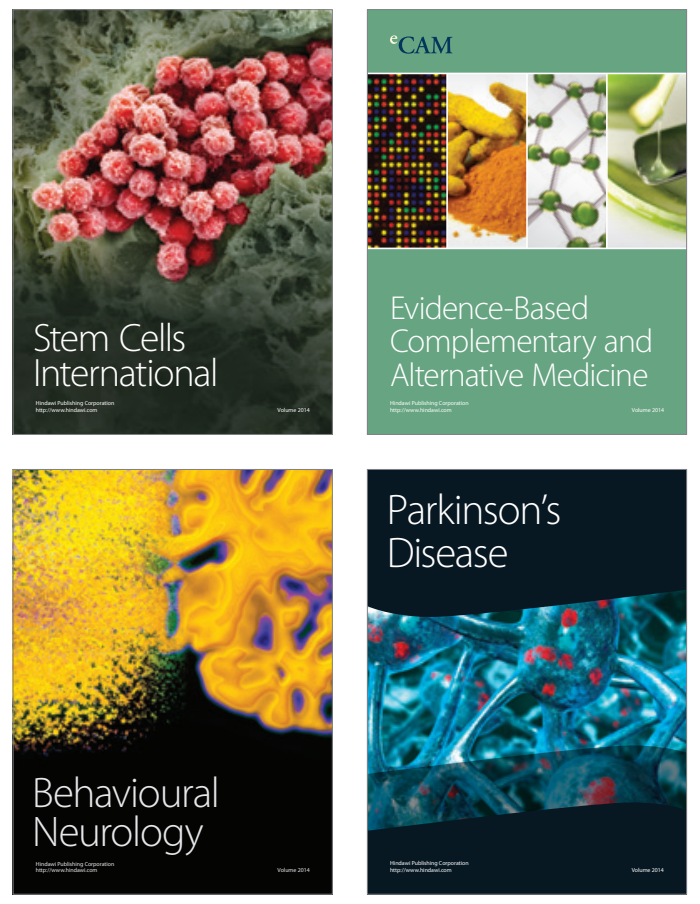
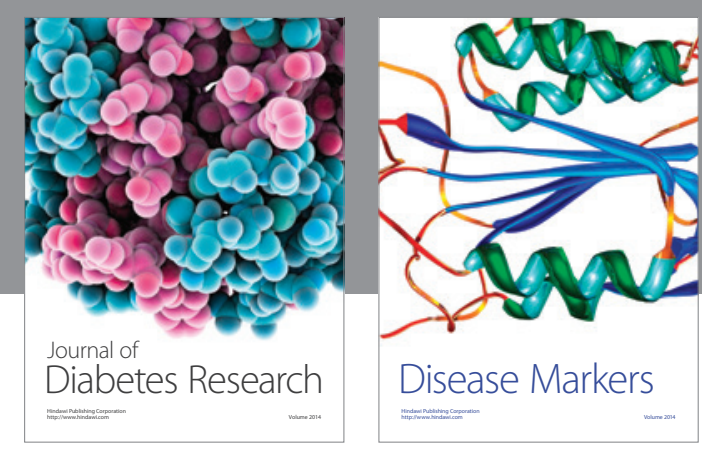

Disease Markers
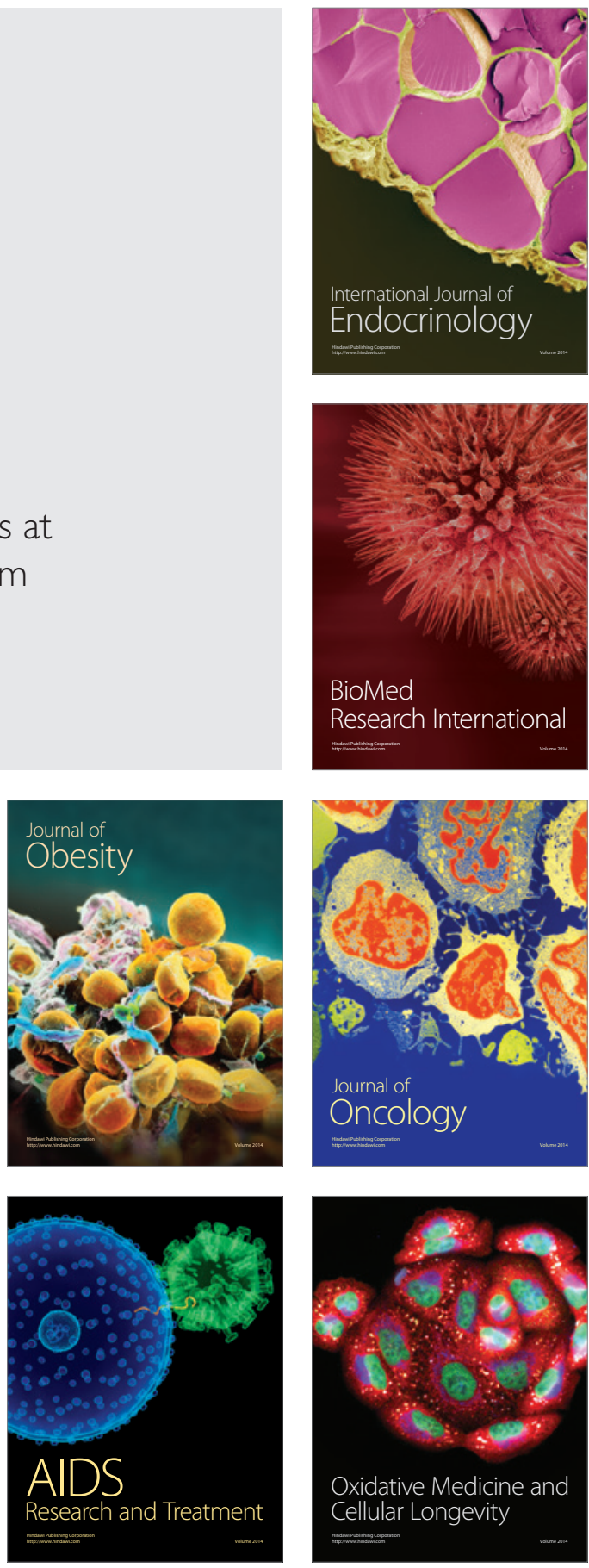